América sin nombre, n. 22 (2017) 37-47

DOI 10.14198/AMESN.2017.22.03

ISSN: 1577.3442 / eISSN: 1989-9831

Fecha de recepción: 05/09/2017

Fecha de aceptación: 25/11/2017
Puede citar este artículo como:

Westphalen R., Yolanda. "El horror de la memoria y las modernidades borderline». El cuento hispanoamericano del siglo XXI. Agustín Prado Alvarado (coordinador). América sin Nombre, 22 (2017): 37-47, DOI: 10.14198/AMESN.2017.22.03

Link para este artículo: http://dx.doi.org/10.14198/AMESN.2017.22.03

\title{
El horror de la memoria y las modernidades borderline
}

\author{
The horror of memory and borderline modernities
}

\author{
Yolanda Westphalen R.* \\ Universidad Nacional Mayor de San Marcos
}

\begin{abstract}
Resumen
El artículo presenta un esbozo de la narrativa breve contemporánea escrita por mujeres. Aborda primero la problemática de la violencia social y de género, tal como esta fue narrada en el Perú durante el periodo del conflicto armado interno a fines del siglo xx; luego dirige una mirada retrospectiva hacia las nuevas generaciones y sus batallas por la memoria, incidiendo en algunas experiencias de la dictadura en Chile y la guerra interna en el Perú. Posteriormente presenta algunas breves incisiones sobre la narrativa argentina reciente y su recorrido por las pesadillas y los miedos enquistados en lo más profundo de la psique, tanto en la esfera individual como colectiva, de personas sometidas al cada vez mayor dominio de una modernidad propia de sociedades borderline.
\end{abstract}

Palabras clave: narrativa escrita por mujeres, violencia social y de género, batallas por la memoria, modernidades borderline

\begin{abstract}
The article presents an outline of the contemporary brief narrative written by women. First it addresses the problem of social and gender violence, as it was narrated in Peru during the period of internal armed conflict at the end of the 20th century; Then there is a retrospective look at the new generations and their battles for memory, focusing on some experiences of the dictatorship in Chile and the internal war in Peru. Subsequently it presents some brief incisions on the recent Argentine narrative and the journey through nightmares and entrenched fears deep within the psyche, both individually and collectively, of people subjected to the ever greater domination of a modernity of Borderline societies.
\end{abstract}

Keywords: written narrative by women, social and gender violence, battles for memory, borderline modernities

La narrativa breve contemporánea escrita por mujeres nos hace transitar por el terreno de la consternación y la angustia, nos sumerge en mundos posibles cargados de horror e intensos sentimientos provocados desde distintas ópticas y mediante procedimientos retóricos disímiles. Dada la enormidad del corpus de cuentos y relatos escritos en este periodo, reduzco mi reflexión a algunos textos de tres escritoras peruanas y una chilena que me permitirán configurar el tópico de la violencia política, además de los relatos de dos

\footnotetext{
* Directora de la Escuela de Literatura de la UNMSM y del Instituto de Investigaciones Humanísticas (IIH). Doctorado en Estudios sobre América Latina en la Universidad de Toulouse Jean Jaurès y Maestría en Literatura Peruana y latinoamericana en la UNMSM. Ha publicado tres libros: Apuntes en voz alta. (Ensayos reunidos); Actas del Coloquio internacional «César Moro y el surrealismo en América Latina» (editora). y CÉSAR MORO: La poética del ritual y la escritura mítica de la modernidad.
} 
jóvenes escritoras argentinas que traen una nueva voz al escenario latinoamericano, perturbadora voz que configura la virulencia de una neurosis afectiva cotidiana que se extiende como una pandemia en el seno de las sociedades latinoamericanas del siglo XXI.

Abordaré primero la problemática de la violencia social y de género, tal como esta fue narrada en el Perú durante el periodo del conflicto armado interno a fines del siglo xx; luego, dirigiré una mirada retrospectiva de las nuevas generaciones y sus batallas por la memoria, ello frente a las experiencias de la dictadura en Chile (1973-1990) y del conflicto armado interno en Perú (1980-2000). Posteriormente, presentaré algunas breves incisiones sobre la narrativa argentina reciente y su recorrido por las pesadillas y los miedos enquistados en lo más profundo de nuestra psique, tanto en la esfera individual como colectiva.

Es importante, en primer lugar, analizar los distintos énfasis en la configuración del imaginario de la violencia en el Perú para establecer las fases por las que ha atravesado su representación simbólica. El recorrido se inicia con el retrato social y la exploración de las posibles causas, gérmenes e indicios de la violencia, de la etopeya de los principales actores del periodo del conflicto armado interno en el Perú: la militante senderista, los niños militarizados y los militares profesionales; no solo el conflicto psicológico de los actores individuales, sino la mirada de importantes sectores sociales ante el enfrentamiento armado y la guerra sucia. «El cazador», "Los días y las horas» $\mathrm{y}$ "Tomando sol en el club» de Pilar Dughi (2017) y «El grito» de Carmen Ollé ${ }^{1}$ transitan esa vía. En «Había una vez un pájaro», Alejandra Costamagna (2013) evoca la experiencia de la dictadura chilena desde la óptica de la cotidianidad y el trastrocamiento emocional de la vida de los hijos de los personajes. Se trata de las batallas por la memoria narradas por esos otros protagonistas de la violencia: los hijos, visión que reconocemos también en La distancia que nos separa de Renato Cisneros y Los rendidos de José Carlos Agüero. Por último, la lupa se localiza y magnifica uno de los aspectos cruciales de la guerra sucia, la violencia de género al interior de la violencia social; la novela corta La sangre de la aurora de Claudia Salazar (2013) traza este camino. Intentaremos esbozar la manera particular cómo cada una de ellas

1. Cuento de Carmen Ollé publicado originalmente en Todo orgullo bumea en la noche (1988). configura el imaginario de la violencia política y militar y los recursos narrativos a los que recurre para transmitir dicha visión.

En La horda primitiva, publicación póstuma de Pilar Dughi (Lima, 1956-2006), se reúnen siete cuentos nuevos con algunos de los mejores de sus dos libros anteriores ${ }^{2}$, aquellos en los que la singularidad de su voz se deja ya sentir. Desde el título, la voz narrativa nos sitúa en el terreno ancestral del malestar y la neurosis reflejados en la conducta de seres con los que convivimos y a los que reconocemos en una sociedad como la peruana y en muchas otras realidades latinoamericanas urbanas y rurales: individuos que nos acechan en una sociedad dislocada por sus traumas históricos, sus tótems y tabúes. He elegido tres cuentos: «Los días y las horas» de La premeditación y el azar (1989) «Tomando el sol en el club»y "El cazador» de Ave de la noche (1996) para presentar el universo que la autora crea para nosotros.

Lo primero que cabe destacar es la manera cómo Dughi nos revela la violencia en la cotidianidad y la cotidianidad de la violencia. El famoso teórico de la guerra Carl von Clausewitz decía que «[l]a guerra es la continuación de la política por otros medios", es decir la continuación de las relaciones de poder y de la lucha por el poder por la vía violenta de las armas; pero ¿se trata solo de la continuación de la política por otros medios o de la continuidad de las relaciones sociales, de clase, etnia y género, por otros medios? Naturalmente, la lucha por el poder, toda forma de poder, está en el corazón de la práctica social humana. Y estas son las relaciones que se revelan en los cuentos de Dughi, los invisibles hilos de la violencia cotidiana de vivir y la exacerbación de ella en las condiciones del conflicto armado interno; pero, sobre todo, y este es el gran aporte de sus cuentos, la construcción psicológica de los personajes, el impacto de la violencia de ellos y hacia ellos.

En «Los días y las horas» se va desde el espacio público, urbano y popular, el de las carretillas, automóviles, ambulantes y personas caminando entre comidas y orines, al espacio doméstico y familiar, el mundo privado de una chica sin nombre, porque en realidad puede ser cualquiera. La alternancia de diálogos y descripciones crea la atmósfera y

2. Este volumen, publicado en 2008 , incluye los cuentos "Los días y las horas» de La premeditación y el azar (1989) $\mathrm{y}$ "Tomando sol en el club» de Ave de la noche (1996). Las citas en este trabajo referidas son tomadas de Todos los cuentos (2017). 
construye social y psicológicamente a los personajes. El diálogo madre/hija alude a las tareas domésticas: barrer, cocinar, hacer las compras, llevar el menú a los obreros en los portaviandas. Los diálogos son a veces tan solo monólogos, frases dichas por la madre y repetidas por la hija; reiteración de lo mismo que las vacía de contenido y enfatiza la continuidad de los días y las horas y se contrapone a otra voz, la de ese muchacho pálido y esquivo cuya voz solemne la llevó a soñar más allá de la terca realidad con romper el reloj.

Lo más importante es quizá el punto de vista en el que se narra la historia, el de una chiquilla cualquiera, gente como uno, en la que se entrelazan todas las violencias -la social, la política, la personal-, secuencias fílmicas de diversos seres sin destino convertidos en simples granitos de arroz:

Saca la bolsa de arroz. Abre un pequeño agujerito en ella [...]. Entonces miles de granitos golpean la superficie de la fuente confundiéndose unos con otros, como pequeños seres sin destino, pero cuya fuerza es tal, tan intensa y tan violenta, que a pesar de su diminuto volumen logran horadar la estrecha abertura de la bolsa de plástico y la amplían, [...] y el torrente de arroz se precipita con increíble velocidad hasta cubrir todo el recipiente, envolviendo la faz de la ciudad, como el partido, piensa. Luego, viene la purificación, se dice, mientras coloca la fuente en el lavadero, bajo el chorro de agua cristalina. [...]. Escurre la masa varias veces y comprueba que el agua vuelve a ser otra vez pura y clara, y el arroz queda limpio, como el partido, piensa (67-8).

El arroz se convierte en la metáfora de la sociedad, compuesta por granitos de pequeños seres sin sentido, pero tan fuertes, que se desbordan al salir de la bolsa. La joven militante encuentra en el cereal la imagen de su apreciación de las fuerzas sociales y el papel purificador del partido frente a ellas, no en la teoría política sino en su hacer cotidiano. El saber y el hacer se entrecruzan y el uno condiciona al otro.

Ella ha descubierto un saber, el del sinsentido de los días y las horas, y por eso actúa. El juego de los espejos y sus imágenes invertidas es el recurso al que la autora apela para mostrar el contraste entre la vecina -que se mira al espejo, se pinta, se maquilla, tiene enamorado y va a la universidad- y ella. La oposición entre la estupidez de aquellos que no se dan cuenta, no saben y creen que tienen un futuro, $y$ aquellos que, como ella, saben que no tienen ningún futuro salvo el que ellos mismos construyan:
La muchacha lleva sus cuadernos en un brazo y la cartera en el otro. Luego buscará un empleo, piensa, hará cola en alguna oficina colmada de gente, esperará hasta que se aburra. Vagará de un sitio a otro y finalmente la titulada universitaria entenderá que no le queda otra cosa que trabajar de cajera en una tienda. La gente es estúpida, se dice (70).

$[\ldots]$

Por lo menos ella está tranquila. Sabe que nada nuevo le espera en esas calles, en esa ciudad que no escogió para nacer ni para vivir. Nada que no haya medido o premeditado (70).

El futuro es la opción que el partido plantea. La voz narrativa configura el universo de ella como sujeto militante en el que la violencia está normalizada y es parte de la vida cotidiana:

[...] ella está huyendo, alejándose de ese cuerpo yerto, extendido sobre la calle, con los ojos abiertos y los labios retorcidos (71).

[...]

Saca el revólver [...]. Lo coloca dentro del pantalón (73).

$[\ldots]$

Y estaba tranquila, tanto que podía comer anticuchos en cualquier esquina mientras aguardaba pacientemente a que llegara su hora (71).

Esta normalización ha sido precedida por un descubrimiento de la muerte en el entorno, en la vida de la madre, en la de la vecina, en la naturaleza artificial de las cosas. Las salidas nocturnas de la joven son para escoger su pequeña mata de geranios y floripondios y dejarlos esparcidos en el cemento de las calles. El esquema pasional del relato va de la rutina de la vida sin perspectivas de la madre, y el desengaño de un futuro en el que solo los ilusos creen, a la creación de una nueva rutina, la de las ejecuciones y la ilusión de un futuro, aunada a la convicción de una causa.

A diferencia de "Los días y las horas», en "El cazador» la historia sigue el esquema pasional contrario, va desde la ilusión del reino de la abundancia hasta la realidad de la guerra, el hambre y la huida. El relato nos ubica primero en un tiempo de leyenda: "en otros tiempos», no en el de "había una vez» sino en el de la utopía de "habrá una vez». "Así sería el reino de la abundancia que llegaría algún día y del que hablaba el partido. Por él era que las masas esperaban» (240). Pero la abundancia ha sido reemplazada por la escasez, se han acabado las provisiones, la 
fuerza principal del partido está siendo asediada por patrullas y sus miembros regresan sin caza ni pesca.

No fueron «secuestrados». El padre llevó voluntariamente a su familia al campamento cuando su hijo tenía 5 años. Ahí, el niño se incorporó a la escuela de formación de cuadros del partido y se le advirtió que cuando cumpliera 12 años pasaría a ser parte de la fuerza principal. La formación del niño es política y militar; a él, y a otros niños como él, les hacen leer y repetir las tesis de Mao y son entrenados para ser soldados. Pero ahora, él y su padre quieren huir. Saben que pueden morir, si no en la huida, al entregarse en la base militar. Al principio, el protagonista tiene vergüenza de aceptar la idea de la huida, pero luego admite su condición de «traidor» sigue el camino del río y se inicia el relato de la cacería.

Tenemos dos historias paralelas, la del escape de Darwin y la de la vida en el campamento. El trayecto de la fuga es también el camino de la conquista de los recuerdos, se nos presentan flashbacks de la vida nómada del campamento, de las incursiones militares, del ajusticiamiento de su amigo Shoreni y su familia, y la voz de su padre convertida en un leitmotiv diciéndole «los mandos se equivocan» (253).

Es curioso que el personaje que tiene que luchar por su supervivencia se llame Darwin. En un momento del relato nos dice: «Le intimidaba estar sin flechas en territorio de fieras» (250). ¿Quiénes son las fieras? Desde su punto de vista, en un momento lo constituye el cerco del ejército; en otro, el ajusticiamiento de los mandos políticos. El ritmo del relato es crucial en la construcción de la atmósfera de miedo del protagonista; nuevamente, la combinación del saber y el hacer son claves para mantener el suspenso del relato. Pero a diferencia del cuento anterior, no se trata de un saber del funcionamiento de las relaciones sociales, sino del conocimiento ancestral de la selva, de sus plantas, animales, sonidos y caminos; saberes que van de la mano con un saber-hacer adquirido recientemente, por un lado, su habilidad para detectar y evadir al enemigo, producto de su entrenamiento militar, y, por el otro, su capacidad de resistir el hambre, aprendida en su vida en el campamento. Se desarrolla una lucha en la que los instintos van de la mano del adiestramiento, de los recuerdos, de la pérdida y de la carencia.

Sin embargo, ¿quién es el cazador y quién la presa? Hay un juego entre ambos roles. Como la voz narrativa adopta el punto de vista de Darwin, asumimos que el personaje que lo persigue, y pertenece también a la fuerza principal, Mardonio, es el cazador, el victimario; pero al final se nos revela el dato escondido de que ambos son tan solo niños, «presentados» o arrepentidos, víctimas o presas de un orden superior. Niños de la guerra, que han tenido que aprender a vivir y a matar para lograr supervivir como especie en el mundo del conflicto armado interno en el Perú de las décadas de 1980 y 1990.

En «Tomando sol en el club» se nos presen$\tan$ nuevos actores de la violencia, los militares y el impacto psicológico de su trabajo en la zona de emergencia. Nuevamente se recurre a la técnica del contraste para mostrar dos facetas del mismo fenómeno: por un lado, el impacto psicológico que deja su actuar en los militares que sirvieron en la zona de emergencia, y, por otra parte, el gran otro social de un sector de la clase media alta y la burguesía que quiere que los militares hagan su trabajo sucio, pero no quiere enfrentarse a la realidad de esos actos y sus consecuencias.

A diferencia de los otros relatos, en este se trata, más bien, de la relación entre el hacer y el no-saber, o mejor dicho, no querer saber. Liliana, la protagonista, es una frívola novia en vísperas de la boda, enarbola la bandera de las «3 Bs»: bronceado, boda y brillante. La voz narrativa contrapone el sol, la luz y la frivolidad de la mujer con la oscuridad de la experiencia en las zonas de emergencia, los comentarios «macabros» de su amiga Susana y el desequilibrio mental de los perpetradores de la violencia, incluido su marido.

Pese a las voces de advertencia de su amiga, Liliana no quiere ver: "Pero ya lleva seis meses de estado de emergencia ¿No le ha afectado? [...] Mi primo está con pesadillas, no te imaginas. Con tratamiento psiquiátrico y ya lo van a dar de baja. Creo que debe de haber sido insoportable [...] No puedo creer que vivan normalmente después de haber estado matando gente -continuó Susana- ¿Él no te ha contado?» (233). «Mi papá ha estado trabajando con Alfredo, ¿ya te contó? A él le preocupa, ¿No te ha dicho nada? [...]. Dice que se niega a ver al psiquiatra» (236). Así, Liliana es incapaz de percibir los indicios y preocupaciones que la amiga le advierte.

Todos se percatan de los cambios operados en Alfredito, tanto en lo físico - "Qué flaco está» (233)como respecto de su estado psicológico, todos menos su novia. Liliana y Alfredo no solo representan una pareja individual, sino la actitud de todo un sector de la población que cierra los ojos y no quiere ver lo que está pasando en la zona de emergencia; de repente, ella se encuentra cara a cara con los ojos de la insania o la locura, y entonces se asusta y se pone a llorar. Ellos simbolizan a la nación burguesa en periodos de 
guerra sucia, el matrimonio entre el brazo armado del poder del Estado y la frivolidad de una clase que quiere que el sistema funcione, pero sin saber cómo lo hace; así, deja matar y luego intenta tapar el sol con un dedo.

La verosimilitud de los distintos relatos es uno de los puntos fuertes de la narrativa de Pilar Dughi. El verosímil real se logra con la combinación de una voz narrativa capaz de construir escenarios cotidianos, el retrato físico y psicológico de sus protagonistas y la alternancia de puntos de vista, desde una mirada externa hasta una focalización interna variable. $\mathrm{La}$ excelencia de su prosa y la naturalidad de sus diálogos contribuyen al efecto mimético.

Carmen Ollé (Lima, 1947), por su parte, nos va a mostrar también a un sujeto militante, a la mujer detrás del pasamontañas, pero para hacerlo opta por otros recursos. En «El grito» recurre a una voz narrativa extradiegética, omnisciente, pero intrusiva, porque emite juicios de valor. Inicia el texto afirmando: «Para los que siempre pensaron que la mujer era un animal de cabellos largos debió parecerles que se había movido la montaña» $(231)^{3}$. El orden ha sido alterado y lo que ahora se escucha es un grito femenino: «Solo que esta vez no era de cualquier garganta, sino la de una muchacha del pueblo, pequeña y cobriza» (231). Edith Lagos convertida en personaje, no real sino ficcional, porque no se trata de un ser de papel individual sino colectivo, no de un ella, sino de un ellas.

El sustantivo del título, remite al de la protesta y la rebelión, pero también al del parto, intenta así subvertir la caricaturización y satanización mediática de las mujeres senderistas, romper el veto de darles voz e imagen en el universo literario a las mujeres que participaron del conflicto armado interno o dirigieron los comandos de aniquilamiento. Construir seres de papel legendarios, encontrar la figura tras la historia épica que nadie narra porque no está permitido. Para poder hacerlo recurre a referencias interdircursivas y metaficcionales respecto de otras imágenes de mujer en la literatura, utiliza argumentos de autoridad para aludir a la oposición entre personajes insignificantes y de temperamento, como Ana Karenina o Madame Bovary. Edith es igual a las demás, salvo la firmeza de su mirada y su grito casi mítico que atraviesa montańas y cerros. El rostro y la voz. "Y la ciudad crujió

3. Todas las citas se toman de la reproducción hecha por Giovanna Minardi en su libro Cuentas... (2000). como un herido que se tambaleara a lo largo de un puente» (233). Para Ollé, la ciudad también está en tránsito, es un puente, pero los que transitan por él están heridos desde el pubis hasta el pecho atravesados por una bayoneta.

Habia una vez un pájaro, de Alejandra Costamagna (Santiago de Chile, 1970), tiene otro punto de mira. Su voz narrativa recupera la memoria de la violencia política de una de las más sangrientas dictaduras del Cono Sur. Lo hace desde la perspectiva de la hija de uno de los actores políticos opositores al régimen y víctima de la represión militar en el poder durante la década de 1970. Pero en la versión breve de la novela En voz baja, el relato no se narra desde la perspectiva épica de los combatientes, sino del efecto devastador de la pérdida del padre en los ámbitos familiar y simbólico: «Mi padre es el protagonista de esta historia, pero mi padre no está» (33). Amanda, la hija, tiene que ir hacia atrás y raspar su cabeza con una astilla para revivir y hacernos revivir el trauma.

La astilla hace huecos por los que se asoma al pasado, flashbacks que construyen un montaje en el que pequeñas secuencias fílmicas tejen retazos de esta historia. El primer fotograma evoca una balacera que arroja a la familia al suelo de la nueva realidad y hace que el padre desaparezca. El ritmo narrativo alterna los espacios públicos y privados de la alteración del orden existente. La cámara se detiene en los martes, las visitas al militante convertido en prisionero, las revisiones íntimas de los carceleros y los sellos tatuados; hace un paneo del recorrido de las niñas por el hogar antes de fijar el objetivo en el cuarto de la madre y los nuevos ruidos que lo pueblan. Orgullo del tatuaje en la escuela y resistencia ante el reemplazo progresivo de la figura del padre en la cama de la madre. Y la nueva desaparición, de la que no se puede hablar porque la muerte acecha. La astilla de Amanda duele y ella es un nuevo tipo de combatiente.

$\mathrm{Al}$ centro de la historia el lenguaje, no como medio de comunicación sino como código encriptado del mundo de los adultos, signos con referentes velados que intentan ocultar la realidad de las nuevas relaciones de poder y las medidas de seguridad para evadirlas: cartas de prisión del padre que incluyen pastiches incrustados como forma de transmitir lo indecible en medio de la desesperación y el quiebre de su resistencia; palabras de cariño inscritas en un papel que hay que quemar porque llegan desde la clandestinidad y el exilio, palabras que devienen en rituales y en fuego sagrado simbólico. Trastrocamiento del orden 
social y familiar somatizado en el trauma bulímico de Amanda, palabras convertidas en pájaros de fuego que arden en la cabeza, en el gas que hay que hacer estallar en el baño una vez enterados de la muerte del padre en un oscuro callejón de Buenos Aires.

Amanda invoca todos sus pequeños actos de transgresión como ofrenda al padre e incluso entrevé la posibilidad de inmolarse en un acto suicida que le permita recuperarlo. Pero la muerte elegida -por ella y por el país- no es la del gran acto de inmolación, sino la de la cámara lenta de las pequeńas resistencias, la de recuperación de la historia entera que ella tendrá que ordenar, la memoria del pájaro de fuego que hablaba en voz baja.

Terminaremos el cuadro de la narrativa de la violencia política con La sangre de la aurora. En la novela corta de Claudia Salazar (Lima, 1976), el universo ficcional ha privilegiado el tópico de la violencia contra la mujer. Las tres protagonistas son violadas durante el periodo del conflicto armado interno en Perú: Marcela, convertida en camarada Marta, la campesina Modesta y la periodista Melanie. Para transmitir la intensidad emocional de la experiencia de la violencia se busca entrelazar la narración con jirones de diálogo, de monólogo interior, de palabras, de sonidos; se construye una suerte de collage de descripciones, narraciones, consignas, citas, pensamientos. Comunicar lo incomunicable implica forzar el lenguaje hasta sus límites, recuperar el carácter pulsional y la capacidad polisensorial del lenguaje, porque no solo hay una relación entre lenguaje, pensamiento y la desarticulación del mismo, o entre narratividad y memoria, sino entre el cuerpo y el lenguaje, entre sensaciones y memoria. Se trata de un cuerpo que siente, piensa, recuerda y comunica.

La estructura de la descripción de los actos de violación busca crear el efecto de la repetición de la misma melodía, solo con algunas variaciones. La dirigente senderista Marta es violada y luego torturada por los soldados, por terruca y subversiva de mierda: "Dale con fuerza, para sacarle su ideología» (68). Melanie es la periodista e intelectual que transita entre dos mundos: el de las amigas burguesas y las universitarias bohemias -mestizas y de sectores populares-, y el mundo del periodismo y el de la libertad sexual. Los guerrilleros la violan por blanquita vendepatria y periodista anticomunista: «Esto te pasa por burguesa, ya verás por dónde te entra la ideología» (66). A Modesta la ultrajan los soldados diciéndole: "Serrana hija de puta, [...] ahora vas a ver lo rico que es que te lo meta un Sargento por detrás, ya nunca más vas a darle de comer a esos terrucos» (69).

Se trata de una violación física y simbólica en el cuerpo de las mujeres y en el de las naciones que existen dentro de nuestro país. «Era un bulto sobre el piso, importaba poco el nombre que tuviera, lo que interesaba era los dos huecos que tenía. Puro vacío para ser llenado. Sin preguntas ni necesitad de respuestas. Ya sabían todo de este bulto. En realidad no les importaba. Lo suficiente eran esas cuatro extremidades de las cuales podía ser sujetado, inmovilizado, detenido». ${ }^{4}$ El cuerpo violado es visto, por lo tanto, como medio de configurar un campo posicional que permite aprehender y conocer el mundo. Se trata, entonces, del cuerpo de la mujer, sí, pero como metáfora del cuerpo social. La posesión forzada del cuerpo, la humillación, la violencia, no es tan solo la del hombre contra la mujer, entendidos como sujetos biológicos, sino el autoritarismo y el poder arbitrario que se imponen contra todos aquellos que no quieren someterse a su orden o que son vistos como bulto, masa y objeto. Se configura así la exacerbación de la violación contra la mujer durante el periodo de la violencia como metáfora de la nación o las naciones violadas a partir de una violencia endémica y estructural.

El ritmo del relato es espasmódico. Es un cuerpo que se contrae involuntariamente, casi por un mecanismo reflejo. Se inicia con la intensidad pulsional del espasmo y luego las convulsiones se intercalan con fragmentos de extensión cognitiva que nos permiten ir configurando el universo de la problemática de la mujer en el seno de una sociedad capitalista y patriarcal que ubica a la mujer, como a los campesinos y comunidades nativas, en el sector de los parias, y, por lo tanto, la identifica con aquellos que luchan contra ese orden. Es el rechazo a su situación de mujer lo que lleva a Marta a luchar por la revolución; son sus exigencias profesionales y la lucha por sus preferencias sexuales las que hacen entrar a Melanie en contradicción con el sistema. Y es la situación de doble explotación de Modesta -como mujer y como campesina-, la que la hace también entrar en contradicción con su marido y contemplar

4. Este fragmento se repite literalmente varias veces en el texto de Claudia Salazar (65, 68 y 69). Ello busca intensificar el efecto y mostrar la reiteración de lo mismo en cada caso narrado, la violación como problema transversal de la mujer en condiciones de guerra. 
el derrumbe de la vida comunal que ella conocía desde siempre.

Sin embargo, la violencia no es presentada solo como tópico, sino como efecto discursivo del lenguaje. El fragmento y la palabra son los dos elementos claves del texto. El lenguaje astillado por la violencia, fragmentado y descoyuntado como los cuerpos de las víctimas de Lucanamarca o Accomarca ${ }^{5}$. La visión del mundo de la teoría marxista convertida en una suma de frases célebres sacralizadas. Palabra astillada, teoría desestructurada y pensamiento inarticulado que nos trae esquirlas de cotidianidad en medio del apagón y la oscuridad; abismo desde donde se articulan las voces de las tres protagonistas. La forma se impone no como la búsqueda de un virtuosismo técnico, sino como expresión de un país fragmentado; perspectivismo que construye una suerte de caleidoscopio e intenta sacarnos de nuestra cómoda cámara fija para hacernos partícipes de un paneo construido a partir de close-ups y planos de detalle de las experiencias individuales de tres mujeres.

La instancia narrativa cambia en el relato de la campesina Modesta, a diferencia de las otras dos protagonistas que hablan en primera persona. En su caso, la narración se configura a partir del uso de la segunda persona, la narradora se dirige a un tú, y es esta voz la que construye así el escenario rural de las yunzas, los trabajos comunales, las ventas en las ferias y la vida en la chacra. Pero a pesar de la construcción de un personaje bastante arquetípico de un mundo andino edificado desde el mundo académico, el campo que se nos presenta dista mucho de ser el espacio de la descripción bucólica. La protagonista no habla directamente, en realidad el diálogo se configura a partir de la mediación de la voz de la narradora; esta, por un lado, naturaliza el universo campesino, pero por el otro recurre al uso de la técnica del micro abierto para mostrarnos un campo

5. La Comisión de la Verdad y Reconciliación peruana fue creada en 2001 para elaborar un informe sobre la violencia armada vivida en el Perú durante el periodo de los ańos 1980-2000. En su Informe final estableció que, el 3 de abril de 1983, miembros del Partido Comunista del Perú-Sendero Luminoso incursionaron en el pueblo de Lucanamarca, en Ayacucho, y asesinaron con hachas, machetes y cuchillos a sesenta y nueve campesinos. Asimismo, que el 14 de agosto de 1985, una patrulla del Ejército asesinó a 62 mujeres, ancianos y niños, comuneros del distrito de Accomarca, también en Ayacucho. Las víctimas de ambas masacres quedaron despedazadas. Ambas matanzas son emblemáticas de este oscuro periodo en el marco del conflicto armado interno en el Perú. atravesado de voces: las de los que quieren carreteras que los vinculen al mercado, las de los que quieren que lleguen los terrucos si les van a regalar vaquitas y los que discuten si es mejor que los defiendan los sinchis o los soldados.

En la novela se juega con la oposición eidética entre la oscuridad de los apagones eléctricos y la luz del pensamiento guía del líder; la melodía de las canciones senderistas y los bailes en las discotecas o las onomatopeyas; los gritos y el ritmo de las balas. Se postula la necesidad de un discurso polisensorial en el que los ojos puedan oler la corrupción de los cadáveres quemados y escuchar el silencio:

El encuadre exacto para mostrar, ¿̇mostrar? ¿a quién? ¿para qué? A veces prefiero no mirar, que sea la cámara el único testigo. El encuadre gritará lo que se prefiere callar. No puedo creerlo, ese olor otra vez. El olor y el silencio acompañan al encuadre aquí y ahora. [...] ¿Cómo puedo hacer que el olor se impregne en la foto? Mil tomas no me bastan. [...] Pero ahí está la historia frente a mi cámara. [...] Que la cámara vea. (60)

Se afirma que la fotografía vale más que mil palabras, pero para Claudia Salazar mil tomas no bastan para transmitir lo que el lenguaje verbal sí puede hacer. Aunque para lograrlo deba potenciar todas sus posibilidades, combinando la lógica discursiva con la explosión pulsional y la ruptura de la sintaxis misma; $\mathrm{o}$, incluso, recurriendo a procedimientos cinematográficos como el montaje de fotogramas hasta construir una película o la compaginación de la imagen y el sonido para lograr el efecto deseado. Semiótica del cuerpo y de las pasiones también graficada en la metáfora sinestésica e hiperbólica de "los mil ojos y los mil oídos» que hacía omnipresente al Partido Comunista del Perú-Sendero Luminoso: "Escuchar $\mathrm{y}$ ver en todas partes, en todas direcciones. Un ojo se llama palabra. Un oído se llama palabra. Otro ojo palabra se llama. ¿Y el otro oído? Así hasta completar los dos mil órganos que están en todas partes. Mi cuerpo se multiplica de esta manera no en los órganos sino en la palabra» (53). Poderosa imagen verbal de la omnipresencia. Las palabras finales de la novela quizá resuman su objetivo: "vivimos muchas voces tantas demasiado todo» (88).

Las voces de estas cuatro narradoras nos presentan distintas imágenes de la mujer durante el periodo de la violencia, tal vez las más interesantes de las que vienen del universo intelectual letrado, pero que habría que cruzar con las que provienen de otros horizontes artísticos y culturales: testimonios, cantos, artesanías, 
representaciones teatrales, esculturas y todas las expresiones que permitan comprender el complejo y contradictorio proceso simbólico de la representación del periodo de la violencia. El efecto de horror se crea en estos cuentos y relatos como consecuencia de una realidad externa de guerras, dictaduras y luchas por el poder que se impone sobre los protagonistas de ambos géneros. Estos son seres de papel provistos de un cuerpo, una experiencia vital, una visión del mundo, dotados de características étnicas y de género; personajes entrañables que habitan pueblos o calles de ciudades reconocibles, pertenecen a una clase social y dialogan con la historia reciente.

A diferencia de las narradoras comentadas - peruanas y chilena-, nos llegan desde Argentina voces de dos nuevas escritoras que configuran el horror como efecto de pesadillas interiores, de los temores más ocultos, de traumas borderline: fisuras tras las que se produce un efecto de extrañamiento y quiebre de la realidad, trazos expresionistas que distorsionan el entorno y revelan una realidad otra, la pesadilla de las metrópolis latinoamericanas trasladada al otrora pacífico y bucólico campo, uno que ya no es más el paraíso perdido de los ecologistas ni un lugar de refugio, sino un espacio limítrofe, caracterizado por un patrón general de inestabilidad económica, social, por angustiantes relaciones interpersonales, una autoimagen devaluada y una afectividad traumática.

En La débil mental, Ariana Harwicz (Buenos Aires, 1977) nos instala desde el inicio en un esquema pasional amor-odio de alta intensidad. El relato empieza con una afirmación en mayúsculas: «NO VENGO DE NINGÚN LADO. El mundo es una cueva, un corazón de piedra que aplasta, un vértigo plano. El mundo es una luna cortada a latigazos negros, a flechazos y a escopetazos» (9). No vengo de ningún lado, solo soy, estoy. Se trata de un estado anímico y social. Violencia del lenguaje que recurre a campos semánticos vinculados a la guerra, las drogas, el sexo, la agresión y el crimen para construir el universo de absoluta desesperación de la protagonista de un pueblo cualquiera de la Argentina rural o suburbana, la protagonista de una modernidad borderline.

La narradora regresa a sus primeros recuerdos de infancia que tienen una marca ineludible de género: "Me invento una vida en las nubes sentada en mi clítoris» (9). Sueños de morfina, de opio, para calmar el dolor y la desesperación de vivir la vida que le tocó vivir. Al centro de la historia, el cuerpo amorfo, sometido, golpeado; el cuerpo épico de la suicida con «la cara hinchada de una adicta en la bañera» (10). Y el inexplicable deseo de que él regrese, que la escupa y le rompa la cara de una bofetada.

Se recurre a la maestría y la crudeza de un lenguaje erótico-tanático, a un mundo reducido a sus necesidades básicas y primarias: comer, mear, copular; al lenguaje pulsional de la violencia, el deseo y la imagen de la absoluta soledad del sexo para configurar el universo de la naturaleza de las relaciones interpersonales y la sordidez de una cotidianidad que quizá ha dejado de ser periférica y marginal. La madre y el sexo; la madre, el abandono y la dureza; la madre y el cordón umbilical que la une a ella. La madre amamantándola, riendo y corriendo tras ella o enseñándole el sexo hasta que se vuelva adicta. La madre imagen de una misma. Ambas abrazadas a un único destino de precariedad, de aislamiento, incomunicación y destierro; cotidianidad incrustada en la violencia y no a la inversa, reproches, conversaciones banales y ásperas. Dos puercas abandonadas soñando con una violación brutal y repetida. Subversión del estereotipo de la relación madre-hija, del mito del deseo de la maternidad. No hay instinto maternal ni inevitables deseos de descendencia y posteridad. Solo la mezcla de recuerdos, las imágenes contradictorias de manzanas azucaradas de antaño, de esporádicas caricias, abrazos y risas ocasionales con el whisky y la resaca compartida del presente. Y la conciencia de que hay otra forma de existir, distinta a la de anochecer con un jarrón de café con calmantes. El estrés de vivir llevado al paroxismo y construido como efecto del lenguaje: comparaciones, alusiones, selección léxica y giros del lenguaje que perturban por la potencia de sus imágenes polisensoriales.

$Y$ en el centro de sus pensamientos, la figura recurrente de él; sus mensajes de texto y la espera compulsiva en el cruce de una autopista cualquiera para tener sexo en un hotel de ruta cualquiera, espacio del encuentro con sus recuerdos de niña feliz y la mano del hombre entrando en ella como si fuera un objeto. La fuerza destructora del sexo y la imposibilidad de las palabras para comunicar. Él, pronunciando justificaciones sobre la imposibilidad de venir tan seguido y ella escuchándolo tan solo con el sobrecogimiento y la devoción de una débil mental que se queda sin palabras para hablar y nombrar las cosas. Tal como la narradora afirma, condición genética sin cura que concibe su ideal de amor como la de un hombre que vive con otra y ama a otra, a cientos de kilómetros.

Para la protagonista, dormirse se asemeja al suicidio; pero despertarse es igual de trágico y pesimista. Vive encerrada en una cueva y sus vecinos son personajes grotescos y anodinos que solo juegan bridge, 
backgammon o duermen echados en sus hamacas. La casa no es más que una pesadilla cálida en la que conviven con bichos y ratones en frascos de formol, tan embalsamados como ellas. Madre e hija en constante proceso de abandono, de intentos de huida y búsquedas mutuas desesperadas, unidas por el desprecio a una vida de trabajos improductivos e infames con jefes que controlan el tiempo en el baño y no permiten celulares; una vida de sueldos mugrientos y la amenaza diaria de la quiebra permanente, un trabajo ambulante que las enfrenta al acoso sexual y la amenaza de muerte, una vida cuyo único final probable -al menos el que ellas vislumbran- es el de ser las más sexis de la morgue.

Mecanismos de defensa y técnicas de defensa personal. Madre e hija intentan huir la una de la otra, mas solo se tienen entre sí desde que la madre y la abuela jugaran a los dados para ver si eran tres. El encuentro con el amor idiota al que se aferra y frente al que sucumbe una y otra vez ha terminado en interferencia y ruido, palabras que le anuncian la fase final del embarazo de la otra. Sueños de rencor y deseos de venganza, ganas de sepultarlo, de desmembrarlo. La fría organización del crimen y el gesto psicótico, el golpe del machete que las une y las libera en el camino sin retorno de un carro en estampida con un cadáver escondido queriendo simplemente que explote todo, destruirlo todo.

Es el esquema narrativo de inanidad y vacío lo que lleva a las protagonistas al frío cálculo de la celada y al paroxismo pasional del crimen. La intensidad y la violencia homicida reflejan, por un lado, la absoluta inestabilidad emotiva, el trastorno límite de personalidad de las dos mujeres; $y$, por el otro, el castigo simbólico a todos aquellos que las sumen en el vacío y la desesperación. El asesinato las transforma en cazadoras furtivas que ocultan en un coche, tan destartalado como sus vidas, el destace de su presa ilegal. Su vida de inanidad solo puede terminar en la muerte, y la única adrenalina que les queda es la de la persecución de policías apostados en busca de un botín de guerra.

Son solo dos mujeres viviendo en una caravana en el campo o las afueras de la ciudad; seres asociales que pueden declararse a favor del fascismo, de la pena de muerte y la quema de caravanas de gitanos. La disposición afectiva de base que determina la relación entre ellas es una situación disfórica, negativa, de frustración, que está en la base del análisis semiótico pasional, de la modulación y cambios de estados de ánimo de ambas. Pero no se trata únicamente del cordón umbilical que une a la madre y a la hija; son muchos otros seres que viven los mismos síntomas disociativos $^{6}$ : hombres y mujeres que se esfuerzan por evitar el abandono y se hunden en sentimientos crónicos de vacío, individuos que viven una gran inestabilidad afectiva en la que se alterna la idealización y la devaluación de las relaciones personales, identidades llenas de ira y frustración, alteradas por el estrés simplemente de vivir. Síntomas neuróticos que intersecan lo individual y lo social, lo público y lo privado.

No es el problema de la historia de dos histéricas pueblerinas, es la imagen de una nación con una autoestima devaluada, en la que la dictadura, las Malvinas, el corralito económico y la creciente ola de feminicidios han dejado impresas en el inconsciente colectivo el profundo trauma de una modernidad signada por la debacle y podredumbre de sus clases dirigentes, por la corrupción, las guerras y las dictaduras, la falta de respeto al medioambiente y la condena a amplios sectores de la población a un destino de parias, marginales y fronterizos tercermundistas.

6. Desde 1938 en el que el psiquiatra norteamericano Adolphe Stern utilizó por primera vez la expresión borderline, se ha recurrido a una gran variedad de términos para referirse a pacientes que no pueden ser clasificados dentro de las categorías de neurótico o psicótico estudiadas tradicionalmente. Según la guía práctica sobre trastorno límite de la personalidad del Departamento de Salud de la Generalitat de Catalunya, publicada en 2011, existen grandes diferencias de conceptualización por la existencia de distintas teorías de la personalidad, pero desde 1980 el Manual de diagnóstico y estadisticas de las enfermedades mentales la incluyó como "trastorno límite de la personalidad» y posteriormente la Clasificación Estadística Internacional la incorporó como un «trastorno de inestabilidad emocional de la personalidad» con dos subtipos: límite e impulsivo. Las características del primer tipo son la baja autoestima, inestabilidad en las relaciones interpersonales que terminan en crisis, los esfuerzos excesivos para no ser abandonados, las reiteradas amenazas o actos de autoagresión y los sentimientos crónicos de vacío. En el caso del tipo impulsivo, predisposición a actuar de forma inesperada y sin tener en cuenta las consecuencias e impulsividad en áreas potencialmente dañinas para sí mismo, actitud interpersonal conflictiva e inestable, sobre todo cuando son censurados, cambios bruscos de estados de ánimo: arrebatos de ira y violencia, ansiedad e incapacidad de controlar estas conductas, dificultad para mantener actividades duraderas que no ofrezcan una recompensa inmediata y un humor inestable y caprichoso. En el texto se recurre metafóricamente a este trastorno de la personalidad para tratar de auscultar los universos disociativos -impulsivos y límites-creados en algunas de las obras reseñadas. 
Ello es lo que hemos venido llamando una modernidad borderline.

El cordón umbilical es también la gran alegoría en Distancia de rescate, de Samanta Schweblin (Buenos Aires, 1978). En este breve, pero intenso relato, se narra una historia profundamente polisémica. La narradora esboza la crisis de unas madres cuyos hijos, infectados por sustancias tóxicas que los carcomen como gusanos, son sometidos a la metempsicosis y dejan de ser sus hijos. La «distancia de rescate» es esa suerte de cordón umbilical invisible que une a las madres con sus hijos, es la distancia que les permite anticipar y las pone en guardia frente al peligro en el que ellos se encuentran. La tragedia de la protagonista es que ese conducto imaginario que la une con Nina no se tensa en el momento preciso, no se tiempla en el instante exacto en el que se produce el dańo. Y como repite constantemente uno de los interlocutores del diálogo, eso es lo único que importa. Los peores temores y miedos de la protagonista se han hecho realidad; las circunstancias de la transformación fueron producto de sus propios errores, pero ella no adquiere conciencia del proceso sino cuando reconstruye la experiencia en su lecho de muerte. El apocalipsis personal es la proyección de sus propios miedos y traumas.

El relato se construye a partir del diálogo entre Amanda, la madre de Nina, y David, el hijo de Carla. Ambos se encuentran en un hospital poco antes de la muerte de la primera. Las preguntas de David apuntan a lograr la autoconciencia de Amanda del momento crucial en el que se produjo la contaminación irreversible y cuáles son las inevitables consecuencias. Las digresiones narrativas de ella forjan la imagen retrospectiva global en la que se revelará el real significado del dato escondido.

La dimensión cognitiva en semiótica designa el universo del saber en la medida que este puede ser narrativizado. Basta que dos actores no dispongan del mismo saber sobre un objeto para que esta modalidad se convierta en un objeto de valor y, en consecuencia, en una puesta en juego narrativa. Según Jacques Fontanille, la cognición aspira al sentido construyendo conocimientos sobre el principio del descubrimiento. Para la lógica de la cognición, el cambio debe ser aprehendido a través de la comparación entre dos mundos, paralelo que permite medir el descubrimiento y el suplemento de conocimiento adquirido a través de él.

En Distancia de rescate se trata de un esquema de extensión cognitiva. Amanda no es consciente ni de cuándo ni por qué pasó lo que pasó. A través de una suerte de diálogo socrático, David indaga y conduce a Amanda a descubrir sus propias respuestas, y en ese recorrido cognitivo nos sumerge en las aguas turbias de una realidad traumática de angustia y neurosis que busca que cada uno de nosotros luche por recuperar la conciencia de la distancia de rescate.

La clave es encontrar qué es lo que envenena y qué efectos produce. El momento climático de la narración nos enfrenta a una doble causalidad: la externa, el agua contaminada, la toxicidad de los fertilizantes de la soja que envenena remotos espacios rurales, mata caballos, patos, perros y deforma los cuerpos físicos de los niños que desfilan como marionetas macabras por el pueblo y son confinados a la sala de espera de una emergencia médica; pero también están envenenadas las relaciones interpersonales, los esposos viven como zombis y los hijos han dejado de serlo, se han transformado en seres extrańos, ajenos, están poseídos por otros con los que se puede convivir pero con los que uno no se identifica. El extrañamiento es repentino e inexplicable. Y se juega con la ambigüedad de las causas de la desesperación y la frustración de las madres, ¿son ellas mismas las que envenenan las relaciones o no se dan cuenta ni del momento ni de las causas del cambio de los hijos y los rechazan? La toxicidad parece rocío y es sutil, engaña, nubla la conciencia y también mata. Es individual y social y se ha normalizado, por eso es tan difícil de detectar. Las sustancias de las que se nutre el cordón umbilical ya no permiten establecer una distancia de rescate, ya no hay rescate.

Hace recordar el cuento de las mariposas de Schweblin, cuando el personaje Calderón atrapa a una para mostrársela a su hija y la aprieta fuerte para que no escape, la inmoviliza para ver los daños en sus alas y cuando, finalmente, ve que ya no puede volar la pisa con firmeza, solo para descubrir que del colegio salen todas las mariposas, menos la suya. Ya no se alimenta uno de los recuerdos del paraíso perdido de la infancia, sino se produce el intercambio de sustancias cada vez más tóxicas; de una realidad cada vez más cruel aunada a la angustia de un presente social de precariedad, violencia y desamparo, materia de la que se nutren hoy amplios sectores sociales de la ciudad y el campo. Mientras mueren los animales y los niños deformes y "migrados» aumentan, las enfermeras y las madres siguen convidando limonada con jengibre y recetando medicamentos contra la insolación. La inconsciencia llevada al límite del humor negro. 
Escritura subversiva y descarnada que nos fuerza a percibir la realidad desde otra perspectiva: la autoconsciencia corrosiva de la violencia, sin tapujos ni contemplaciones. En los últimos cincuenta años, América Latina ha padecido dictaduras sangrientas (Chile, Argentina, Uruguay, Bolivia), conflictos armados internos (Perú, Colombia); en sus sociedades se ha profundizado la brecha de desigualdad y la violencia estructural del narcotráfico, el crimen organizado, la violencia doméstica, el feminicidio, la inseguridad ciudadana, la polarización política y la corrupción, fenómenos que se han entronizado en las metrópolis y megalópolis y se extienden hoy incluso a las pequeñas ciudades a lo largo y ancho del continente. La narrativa escrita por mujeres nos sumerge en la brutalidad y la ternura de los pliegues de la memoria nos recuerda una vez más que no hay mañana sin ayer, pero también nos revela la sensibilidad artística de las escritoras posconflicto para percibir y construir universos simbólicos plagados de neurosis afectivas, no solo individuales, sino sociales, imaginarios convulsivos producidos por el mero efecto del lenguaje.

Parafraseando el título del extraordinario primer libro de cuentos de Samanta Schweblin, el núcleo de disturbio al que alude la narrativa breve de las distintas voces reseñadas es el de las sociedades latinoamericanas. Sus modernidades deformes y sus relaciones sociales e interpersonales cada vez más violentas pueden ser alegóricamente representadas por "Matar a un perro", uno de los más estremecedores cuentos de la autora. Como el protagonista, los lectores nos sentimos completamente abandonados en una plaza rodeada de perros violentos. Jaurías en acecho y volcanes a punto de estallar, rocas fundidas que emergen de las más profundas capas de la memoria y de los distintos sustratos de la corteza social y nos plantean la incógnita del curso que seguirá el magma, erupción que surge hoy compulsivamente en la narrativa latinoamericana escrita por mujeres y nos muestra los múltiples rostros de la nueva identidad latinoamericana.

\section{Referencias bibliográficas}

AgüERo, José Carlos. Los rendidos. Lima: Instituto de Estudios Peruanos, 2014.

Cisneros, Renato. La distancia que nos separa. Lima: Planeta, 2015.

Costamagna, Alejandra. En voz baja. Santiago de Chile: LOM, 1997.

Costamagna, Alejandra. Habia una vez un pájaro. Santiago de Chile, Editorial Cuneta, 2013.

Comisión de la Verdad y Reconciliación. INFORME FINAL, 9 tomos. Lima: CVR.

Dughi, Pilar. La premeditación y el azar. Lima: Editorial Colmillo Blanco, 1989.

Dughi, Pilar. Ave de la noche. Lima: Peisa, 1996.

Dughi, Pilar. La horda primitiva. Lima: Peisa, 2008.

Dughi, Pilar. Todos los cuentos. Lima: Campo Letrado Editores S.A.C., 2017.

Fontanille, Jacques. Semiótica del discurso. Lima, Fondo Editorial de la Universidad de Lima, 2001.

Fontanille, Jacques. Soma y Sema. Figuras semióticas del cuerpo. Lima: Fondo Editorial de la Universidad de Lima, 2008.

Guía de práctica clínica sobre trastorno límite de la personalidad. Agència d'Informació, Avaluació i Qualitat en Salut. 1. ${ }^{a}$ edición, junio 2011, Barcelona. http:// www.guiasalud.es/GPC/GPC_482_Trastorno_ Limite_Personalidad.pdf

Harwicz, Ariana. La débil mental. Lima: Animal de Invierno, 2014.

Ollé, Carmen. Todo orgullo humea en la noche. Lima: Lluvia Editores, 1988.

Ollé, Carmen. «El grito». En Giovanna Minardi, Cuentas: narradoras del siglo XX. Lima: Ediciones Flora Tristán/ El Santo Oficio, 2000: 231-233.

SAlaZAR, Claudia. La sangre de la aurora. Lima: Animal de invierno, 2013.

Schweblin, Samanta. El núcleo del disturbio. Lima: Editorial Santuario, 2006.

Schweblin, Samanta. Distancia de rescate, $2 .^{\mathrm{a}}$ edición. Buenos Aires: Random House, 2015. 
